\section{Summary and Conclusions}

The perinatal mortality for 5,893 single births occurring in the Oxford area in 1962 has been studied in relation to the local organization of maternity services. The perinatal mortality rate for single births was 23 per 1,000 , and 25 per 1,000 for all births, results which compare favourably with those in other parts of England and Wales.

Of the mothers $48 \%$ had been booked for consultant care, $51 \%$ for care under general practitioners either at home or in G.P. maternity units, and a little under $1 \%$ had not been booked for any type of care. When the mothers were classified into three risk groups according to features evident at the time of booking (maternal age, parity, and a previous history of stillbirth) it was found that $57 \%$ of risk group I (all women aged 35 years or more, nulliparae aged 30 years or more, multiparae having had four or more children, and women with a past history of stillbirth), $58 \%$ of risk group II (nulliparae under 30 years), and $37 \%$ of the remainder had been booked for consultant care.

For risk groups I and III the perinatal mortality rate was higher in consultant- than in G.P.-booked cases, a situation which at least in part reflects selection of difficult cases for consultant care within these groups. For young nulliparae, however (risk-group II), the perinatal mortality for legitimate births in 1962 was slightly higher in mothers booked for G.P. care $(24$ per 1,000$)$ than in those booked for consultant care (21 per 1,000). This group also experienced the highest rate of emergency transfer to consultant care late in pregnancy or in labour (13\%).

In a study of 55 general practices a wide variation was found between practices in the proportions of mothers booked for consultant care. This was also present when each risk group was considered separately. Two important factors which influenced this variation were found. Firstly, the presence of a local G.P. obstetric unit greatly reduced the proportion of mothers booked for consultant care in each risk group.
Secondly, when a G.P. obstetric unit was accessible to practices, increasing distance from a consultant unit further depressed the proportion of mothers in each risk group booked for consultant care. A reduction in consultant bookings with distance did not occur where no G.P. unit was accessible to practices.

The perinatal mortality was significantly higher in practices with access to G.P. units $(28$ per 1,000$)$ than in those without such access (19 per 1,000), and further analysis showed that this difference was limited to mothers in risk groups I and II. No evidence was found to support the hypothesis that the higher mortality in practices with access to G.P. units was due to an inherently less favourable population from the obstetric point of view, nor was it possible to show that differences in the arrangements for obstetric care were responsible.

We wish to thank the medical officers of health, obstetricians, general practitioners, midwives, and matrons of the maternity units in the Oxford Record Linkage Study area for their helpful co-operation, without which this study would not have been possible. We are particularly grateful to Miss A. M. Lamb, Miss P. Millar, and Miss E. Richards, the supervisors of the three domiciliary midwifery services of the area, for their assistance in the collection of information about mothers who received domiciliary obstetric care.

REFERENCES

Butler, N. R., and Bonham, D. G. (1963). British Perinatal Mortality Survey of 1958. Perinatal Mortality (1st Report of the 1958 British Perinatal Mortality Survey under the auspices of the National Birthday Trust Fund). Livingstone, Edinburgh and London.

Godber, Sir George (1964). Circular letter from Ministry of Health to Maternity Liaison Committees (Ref. No. E/M192/2).

Ministry of Health (1959). Report of the Maternity Services Committee. H.M.S.O., London.

H.M.S.O., London. (1963). Report on Confidential Inquiries into Materna England and Wales, 1958-1960. H.M.S.O., London.

National Health Service (1962). A Hospital Plan for England and Wales. H.M.S.O., London.

Registrar-General (1964). Statistical Review of England and Wales for 1962. H.M.S.O., London.

\title{
Plasma Renin Concentration in Human Hypertension III : Renin in Relation to Complications of Hypertension
}

\author{
J. J. BROWN,* M.B., B.S., B.SC., M.R.C.P.; D. L. DAVIES,* M.B., B.S. \\ A. F. LEVER,* M.B., B.S., B.SC., M.R.C.P. ; J. I. S. ROBERTSON,* M.B., B.S., B.SC., M.R.C.P.
}

Brit. med. F., 1966, 1, 505-508

We have previously shown, in a large series of patients with hypertension, that plasma renin concentration is inversely related to plasma sodium, and that this relationship is apparently independent of aetiology, severity of the hypertension, and treatment. A separate analysis has also been made of plasma renin in relation to aetiology (Brown et al., 1965a, 1965 b, 1965c). In the present paper we consider variations in renin and sodium in relation to certain complications of the hypertension-namely, the malignant phase, cardiac failure, and renal failure.

The clinical material and the methods used in this study are as given previously (Brown et al., 1965b). As the hypertensive series has enlarged progressively since the previous papers were prepared, data on additional cases have been included (cf. Brown et al., 1965b, 1965c ; Barraclough et al., 1965). The present results are based on a study of 293 hypertensive patients.

* Medical Unit, St. Mary's Hospital, London.

\section{Malignant Phase of Hypertension}

The term "malignant hypertension" has been used in slightly different senses by previous writers, but generally implies severe elevation of the blood-pressure with very limited prognosis if untreated. Ophthalmoscopically, the malignant phase is characterized by retinal haemorrhages, exudates, and papilloedema. Histologically the essential lesion is fibrinoid arteriolar necrosis, especially of the afferent glomerular arterioles.

\section{(a) Relationship between Retinopathy and Renal Histology}

Renal histology was studied in 104 patients, in nearly all instances on biopsy material. Fibrinoid arteriolar necroses were found in 11 out of 16 cases with bilateral retinal haemorrhages, 
exudates, and papilloedema ; in 8 out of 19 with bilateral haemorrhages and exudates but without papilloedema; and in 7 out of 69 without any of these ocular lesions.

We have diagnosed malignant hypertension either on the presence of bilateral retinal haemorrhages and exudates, irrespective of papilloedema, or on the demonstration of fibrinoid necroses. In no cases of the series was an alternative explanation for these ophthalmoscopic or histological appearances found.

\section{(b) Hypertension with Retinopathy}

This has been taken as the presence of bilateral retinal haemorrhages or exudates or both, irrespective of papilloedema. The classification of Keith et al. (1939), which has been subject to serious criticisms (Pickering, 1955 ; Platt, 1956), has not been used.

Hypertensive Retinopathy in Renal Artery Stenosis.-The first column of Fig. 1 shows plasma renin concentrations in 25

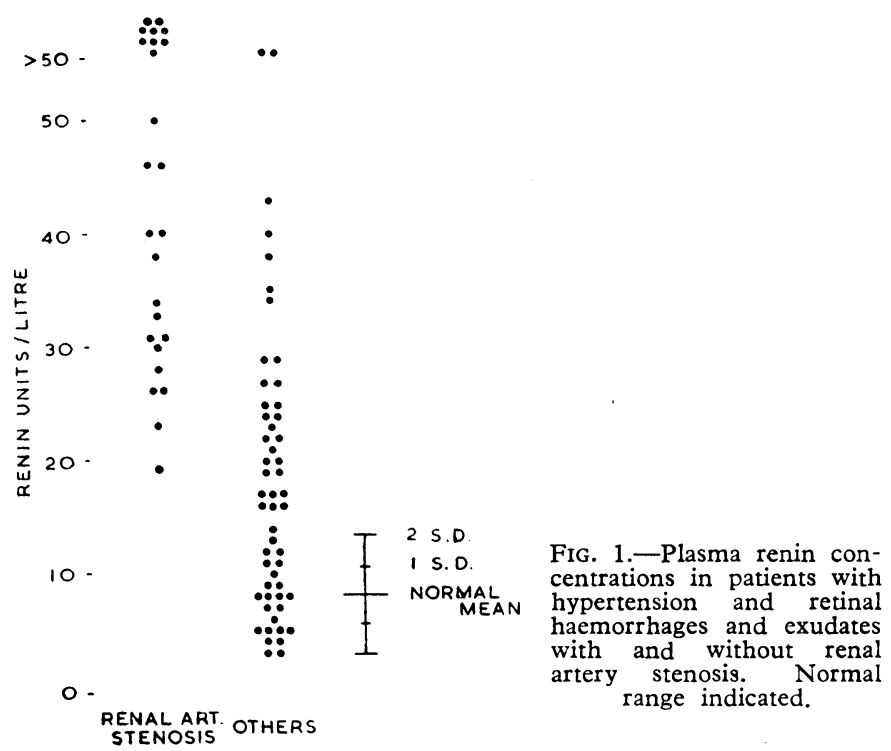

patients with retinopathy and renal artery stenosis, the latter diagnosis being made on the arteriographic demonstration of renal artery narrowing, together with characteristic findings on ureteric catheterization studies (Brown et al., 1960, 1964b). Renin was raised in all these patients, ranging from just above normal (19 units/1.) to values a hundred times higher (highest 1,920 units/1.). The distribution of these results was, as we have reported previously, quite different from that in 19 patients with renal artery stenosis but without retinopathy, where plasma renin ranged from low normal up to 23 units $/ 1$, and just overlapped the lowest renin levels of the group with retinal lesions (Brown et al., 1965c, 1965d). Since renin concentration in renal artery stenosis was found to be related positively to the severity of the lesion and negatively to the plasma sodium level, the patients with retinopathy shown in the first column of Fig. 1 represent the cases with high renin, low sodium, and generally more severe stenoses (see Brown et al., 1965c).

Hypertensive Retinopathy in Cases Without Renal Artery Stenosis.-The second column of Fig. 1 shows plasma renin concentrations in 53 patients with retinopathy but without renal artery stenosis as defined above. It can be seen that plasma renin concentrations in these cases ranged from abnormally low to very high (from 2.5 to 240 units/1.). Once more a very close reciprocal relationship was found between plasma sodium and renin concentration $(\mathrm{r}=-0.710 ; \mathrm{P}<0.001)$. Though none of the 53 cases had received effective treatment at the time of sampling, only 12 were strictly untreated. In these 12 cases both renin and sodium ranged from abnormally low to abnormally high, and the inverse relationship between the two measurements was again remarkably close $(r=-0.984$; $\mathrm{P}<0.001$ ). These results make it unlikely that the findings in the group as a whole could have resulted from any previous treatment.

Renal disease, either primary or secondary to the hypertension, was common in these patients, and several with high renin and low plasma sodium showed features of the "hyponatraemic hypertensive syndrome" (Brown et al., 1965b). However, there remained numerous examples with retinopathy and either normal or low plasma renin concentration, and these provided a contrast to the group with renal artery stenosis and retinopathy, where renin was in all cases high (Fig. 1). Depression of plasma renin could occur with congestive cardiac failure or as a result of sodium overloading, to which patients with renal failure would be particularly susceptible (see Fig. 3). The second column of Fig. 1 contains instances of both these situations. Nevertheless, there were a few patients with retinopathy, hypernatraemia, and low plasma renin who did not show evidence of cardiac or renal failure. This combination would be anticipated occasionally in patients with primary overactivity of the adrenal cortex, since it is well established that the malignant phase, though uncommon, can supervene in both Cushing's syndrome (MacMahon et al., 1934; Pickering, 1955) and Conn's syndrome (Brill et al., 1960 ; Kaplan, 1963 ; Brown et al., 1964c ; Luetscher, 1964).

\section{(c) Fibrinoid Lesions without Retinopathy}

Fibrinoid arteriolar lesions were found in the absence of retinal lesions in seven patients, in all of whom the renin concentration was normal or abnormally low (mean $=6.4$; S.E. $=1.8$ units/1.). Two of these had Conn's tumours (Brown et al., 1964c), and this diagnosis is probable in the third, not yet submitted to operation, who is at present controlled with oral spironolactone. Two further patients were in chronic renal failure due respectively to polycystic disease and glomerulonephritis. Fibrinoid necroses were present in renal arterioles in all except the last instance, where they were found only in the adrenal at post-mortem examination.

\section{(d) Sodium, Potassium, and Aldosterone in Malignant Hypertension}

In the entire series 23 patients had either retinopathy or fibrinoid lesions or both, together with a plasma potassium below $3.5 \mathrm{mEq} / 1$. These were divisible into two distinct groups -17 with abnormally high renin concentrations and six with renin either subnormal or in the low normal range (Fig. 2).

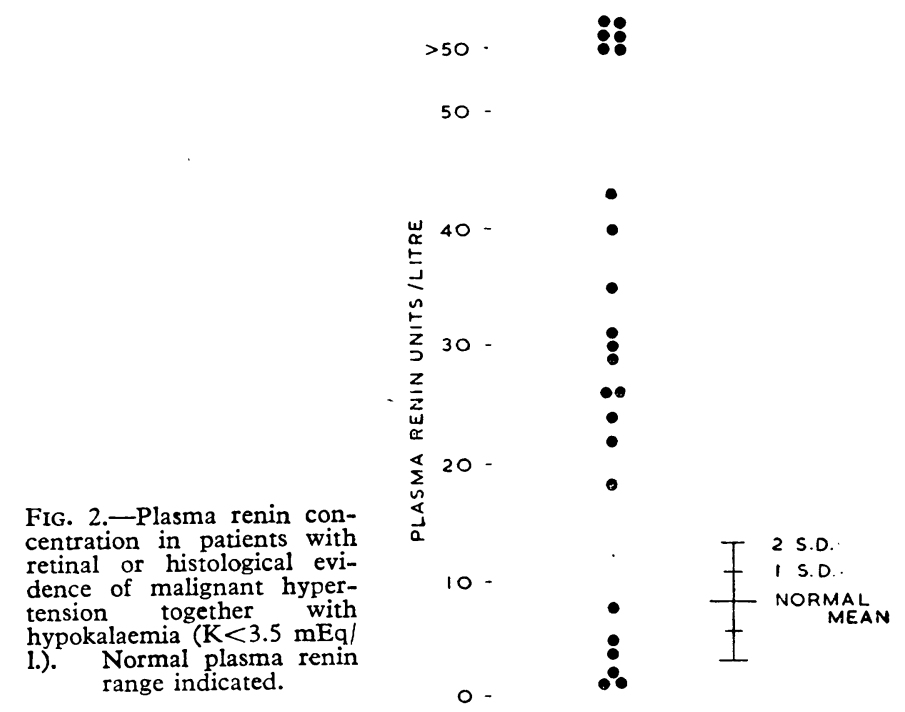


Excess aldosterone secretion or raised plasma aldosterone was demonstrated in four of the group with low renin and in three of those with high renin.

While those cases with low renin resembled Conn's syndrome in a tendency to increased plasma sodium (mean $\mathrm{Na} 143.9$ $\mathrm{mEq} / \mathrm{l}$.), those with high renin usually had low plasma sodium (mean $134.8 \mathrm{mEq} / 1$.).

\section{Relation of Present Findings to Measurements of other Components of the Renin-Angiotensin System}

We have discussed elsewhere the difference between measurements of renin concentration, angiotensin concentration, and "renın activity," and have emphasized that these may not necessarily increase together (Brown et al., 1964d, 1965b, 1966). Moreover, very diverse methods have been used in making these estimations. Despite the reservations it is nevertheless of interest to compare the present findings with the results of angiotensin and " renin activity" estimations in other series.

Kahn et al. (1952) reported a significant increase in circulating angiotensin in malignant hypertension. Genest et al. (1964) and Morris et al. (1964) did not, however, confirm these findings.

"Renin activity" was found to be increased in a proportion of cases of malignant hypertension by Yoshinaga et al. (1963), Helmer (1964), Fitz and Armstrong (1964), Kirkendall et al. (1964), Fasciolo et al. (1964), and Genest et al. (1964). Kirkendall et al. (1964) found a suggestion of lower serum sodium levels in their patients. Sodium measurements were not reported in the other series, and there may therefore be less conflict between the various findings than is at first apparent. More difficult to explain at present is the finding by Genest et al. (1964) of increased " renin activity" in plasma in which angiotensin was undetectable. Genest et al. (1964) could also find no correlation between plasma angiotensin and urinary aldosterone excretion in patients with hypertension.

\section{Renin and Angiotensin in the Pathogenesis of the Malignant Phase}

Several workers have found evidence in extracts of ischaemic kidneys of a factor capable of increasing the permeability of arterioles and capillaries when injected intravenously (see Winternitz et al., 1940 ; Giese, 1962, 1963, 1964a, 1964b ; Asscher and Anson, 1963 ; Masson et al., 1964). While the relationship of this "vascular permeability factor" (or factors) to renin has not been clearly established, it seems possible at present that it could contribute to the vascular lesions of malignant hypertension.

Laragh et al. (1963) and Conn et al. (1964) have suggested that a combination of both increased plasma angiotensin and aldosterone may be required for the development of the malignant phase.

The present findings show that increased plasma renin concentration is not an invariable accompaniment of either the ophthalmoscopic or histological stigmata of malignant hypertension. While this is evidence against the theories of Laragh et al. (1963) and of Conn et al. (1964), it does not finally exclude them, since renin concentration cannot necessarily be equated with angiotensin concentration (Brown et al., 1965b).

Our results accord with the view that the vascular lesions are predominantly a consequence of increased intra-arterial pressure (see Wilson and Pickering, 1938 ; Wilson and Byrom, 1939 ; Byrom and Dodson, 1949 ; Pickering, 1955 ; Byrom, $1960,1963 a, 1963 b)$. However, intravenous infusions of angiotensin have been found to cause constriction of retinal vessels (Dollery et al., 1963), and Pears and Pickering (1960) described fundal changes indistinguishable from those of malignant hypertension in patients suffering severe gastro-intestinal haemorrhage, a situation in which plasma renin concentration has been found increased (Brown et al., 1965e). Pears and Pickering suggested that focal retinal anoxia could be the mechanism common to both situations, and it is possible that the retina might develop hypertensive lesions more readily than other tissues if plasma angiotensin was increased. It is notable that renal and adrenal fibrinoid lesions without accompanying retinopathy were found in several patients having either normal or low plasma renin.

\section{Cardiac Failure}

Plasma renin concentrations in nine hypertensive patients with raised jugular venous pressure and peripheral oedema were $3,4,5.5,13,16,16,20,26$, and 48 units/1. Evidence of leftsided heart failure was present in the patients with values of 3 and 20 units/1. The three highest levels in the group were found in cases receiving diuretic therapy. Retinal or histological evidence of the malignant phase was found in five of the nine.

These results permit only the most limited interpretation, but they are consistent with the concept of an inverse relationship between renin and sodium. They agree also with findings in other forms of cardiac failure, in which plasma renin concentration has not unusually been low or normal in untreated congestive failure, rising as the patient becomes free from oedema, and sometimes progressing to abnormally high levels after vigorous diuretic therapy (Brown et al., 1965d, 1966). In other cases of untreated congestive failure the opposite pattern has been observed; initially high concentrations of both plasma renin and plasma aldosterone have been found, both returning to normal with relief of the oedema.

It is notable that studies of aldosterone production in congestive cardiac failure have similarly given variable results, though if the metabolic clearance rate was impaired because of hepatic congestion, high plasma aldosterone concentration could be maintained without a rise in secretion rate (see Deming and Luetscher, 1950 ; Muller et al., 1956 ; Wolff et al., 1957; Ulick et al., 1958 ; Tait et al., 1962 ; Laragh, 1962 ; Luetscher et al., 1963 ; Urquhart and Davis, 1963 ; Sanders and Melby, 1964).

\section{Chronic Renal Failure}

Of 51 patients with blood urea persistently higher than 45 $\mathrm{mg} . / 100 \mathrm{ml} .23$ had bilateral retinal haemorrhages and exudates, and three others had fibrinoid arteriolar lesions without retinopathy. No evidence of the malignant phase was found

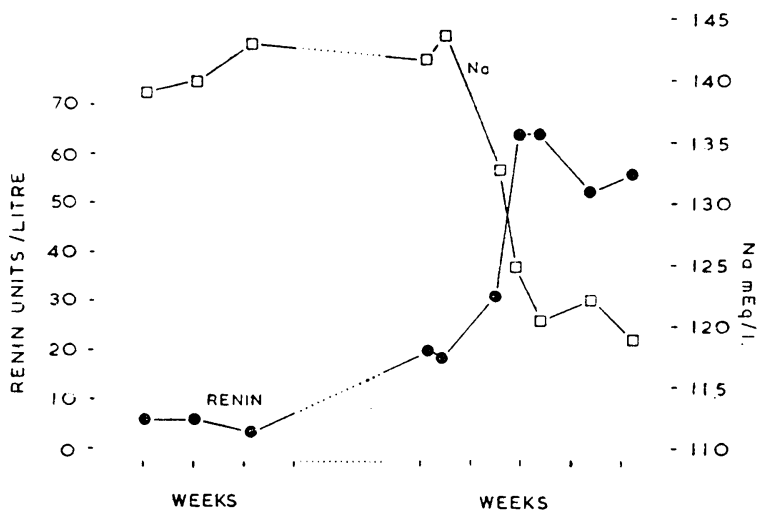

FIg. 3.- Serial estimations of plasma $\mathrm{Na}$ and renin in a man with malignant hypertension and chronic renal failure. The fall in $\mathrm{Na}$ and rise in renin was associated with diuretic therapy. Although the two measurements are inversely related, plasma renin concentration is not always the same for a given $\mathrm{Na}$. This indicates that renin is not governed solely by plasma Na level. 
in the remaining 25. Plasma renin concentration varied from abnormally low to abnormally high both in those patients with and in those without evidence of the malignant phase, although elevated renin was more common in the former.

The inverse relationship between renin and sodium in the patients with chronic renal failure was highly significant (76 pairs of observations in 41 cases ; $\mathrm{r}=-0.489 ; \mathrm{P}<0.001$ ). The wide variation in plasma renin concentration is probably a reflection of the instability of sodium balance in chronic renal failure, sodium overloading or depletion readily occurring and leading to corresponding swings in plasma renin. This is exemplified in Fig. 3, which shows serial estimations of renin and sodium in one patient with malignant hypertension and advanced renal failure. It seems also that renin production may be unimpaired even when excretory function is grossly disordered.

In two further patients with advanced renal failure, bilateral nephrectomy was followed by a fall in plasma renin to below 1.5 units $/ 1$. within 48 hous. ${ }^{1}$. This observation is in accord with earlier studies in the rabbit (Lever and Robertson, 1964). It remains to be determined whether in these circumstances low concentrations of renin from extrarenal sources may circulate in plasma.

\section{Summary}

Variations in plasma renin concentration were studied in relation to some of the complications of hypertension.

The close reciprocal relationship between plasma renin concentration and plasma sodium is again emphasized.

In the malignant phase renin concentration was variously low, normal, or high.

In patients with both renal artery stenosis and malignant hypertension plasma renin was in all instances high.

Plasma renin was elevated also in many patients with malignant hypertension without renal artery stenosis; but numerous instances of normal, and a few of abnormally low, renin concentrations were seen in this group, both in cases with and in cases without renal or cardiac failure.

While some patients with untreated hypertensive heart failure presented with hypernatraemia and low renin, as in other forms of congestive cardiac failure, this pattern may not be invariable.

In patients with chronic renal failure very wide variations in plasma renin concentration occurred.

Plasma renin fell to extremely low concentrations in two cases after bilateral nephrectomy.

We wish to thank the many clinicians who collaborated in these studies, and especially Professor W. S. Peart, Professor H. E. de Wardener, Dr. M. A. Barraclough, and Dr. V. Wynn. Technical and secretarial help was provided by $\mathrm{Mr}$. Malcolm Tree, $\mathrm{Mr}$. Patrick Trust, Mr. George Todd, Mr. Alan Jones, Mr. Robin Waller, Mrs. D. M. Roberts, and Mrs. E. M. Maxwell. The work was supported by grants from the Medical Research Council, the Wellcome Trust, and Pfizer Ltd.

${ }^{1}$ It will be noted that this figure is higher than the sensitivity limit quoted for the method (Brown et al., 1964a). This is because less than $25 \mathrm{ml}$. plasma was available in these samples.
REFERENCES

Asscher, A. W., and Anson, S. G. (1963). Nature (Lond.), 198, 1097 Barraclough, M. A., Bacchus, B., Brown, J. J., Davies, D. L., Lever, A. F., and Robertson, J.I. S. (1965). Lancet, 2, 1310

Brill, G. C.., Creamer, B., Mills, I. H., and Pullan, J. M. (1960). Brit. med. F., 2, 990.

Brown, J. J., Owen, K., Peart, W. S., Robertson, J. I. S., and Sutton, D. (1960). Ibid., 2, 327

Davies, D. L., Lever, A. F., Robertson, J. I. S., and Tree, $M$. (1964a). Biochem. F., 93, 594 .

Matthew, G. K., and Robertson, J. I. S. (1964b). Clin. Sci., 26, 381.

Davies, D. L., Lever, A. F., Peart, W. S., and Robertson, J. I. S (1964c). Brit. med. F., 2, 1636.

- (1966). Postgrad. med. 7 . In press.

- and Tree, M. (1964d). Biochem. F., 93, 3c.

$--(1965 \mathrm{a})$. F. Endocr., 32, v.

-- (1965b). Brit. med. 7., 2, 144.

$-(1965 c)$. Ibid., 2, 1215

Symposium Paris (1965). L'expansion Scientifique. C.I.H.T.A Paris (July 1965).

182, 649 - and Verniory, A. (1966). F. Physiol. (Lond.),

Byrom, F. B. (1960). Lectures on the Scientific Basis of Medicine, 8 , 256. University of London.

(1963a). Lancet, 1, 516.

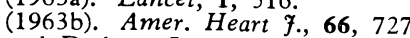

and Dodson, L. F. (1949). Clin. Sci., 8, 1.

Conn, J. W., Knopf, R. F., and Nesbit, R. M. (1964). In Aldosterone, edited by E. E. Baulieu and P. Robel, p. 327. Blackwell, Oxford.

Deming, Q. B., and Luetscher, J. A. (1950). Proc. Soc. exp. Biol. (N.Y.), 73, 171 .

Dollery, C. T., Hill, D. W., and Hodge, J. V. (1963). 7. Physiol. (Lond.), 165, 500.

Fasciolo, J. C., De Vito, E. Romero, J. C., and Cucchi, J. N. (1964). Canad. med. Ass. F., 90, 206

Fitz, A. E., and Armstrong, M. L. (1964). Circulation, 29, 409.

Genest, J., Boucher, R., de Champlain, J., Veyrat, R., Chretien, M. Biron, P., Tremblay, G., Roy, P., and Cartier, P.'(1964). Canad. med. Ass. 7., 90, 263.

Giese, J. (1962). Acta path. microbiol. scand., 56, 399.

- 1963). Ibid., 59, 417 .

(1964). Ibid., 62, 481.

(1964b). Ibid., 62, 497

Helmer, O. M. (1964). Canad. med. Ass. 7., 90, 221.

Kahn, J. R., Skeggs, L. T., Shumway, N. P., and Wisenbaugh, P. E. (1952). 7. exp. Med., 95, 523

Kaplan, N. M. (1963). Nezw Engl. F. Med., 269, 1282

Keith, N. M., Wagener, H. P., and Barker, N. W. (1939). Amer. f. med. Sci., 197, 332 . Kirkendall, W. M., Fitz, A., and Armstrong, M. L. (1964). Dis. Chest,

Laragh, J. H. (1962). Circulation, 25, 1015.

Cannon, P. J., and Ames, R. P. (1963). Ann. intern. Med., 59, 117. er, A. F., and Robertson, J. I. S. (1964). F. Physiol. (Lond.), 170, 212 .

Luetscher, J. A. (1964). Medicine (Baltimore), 43, 437

Camargo, C. A., Cohn, A. P., Dowdy, A. J., and Callaghan, A. M. (1963). Ann. intern. Med., 59, 1

MacMahon, H. E., Close, H. G., and Hass, G. (1934). Amer. F. Path. 10,177

Masson, G. M. C., Kashii, C., and Panisset, J. C. (1964). Canad. med. Ass. 7., 90, 231. Morris, R. E., Robinson, P. R., and Scheele, G. A. (1964). Ibid., 90,
272 .

Muller, A. F., Riondel, A. M., Manning, E. L., and Mach. R. S. (1956). Schweiz. med. Wschr., 86, 1335 .

Pears, M. A., and Pickering, G. W. (1960). Quart. 7. Med., 29, 153.

Pickering, G. W. (1955). High Blood Pressure. Churchill, London.

Platt, R. (1956). Symposium on Clinical Management of Hypertension, edited by $M$. Hamilton and A. E. Doyle, p. 52.

Sanders, L. L.., and Melby, J. C. (1964). Arch. intern. Med., 113, 331.

Tait, J. F., Little, B., Tait, S. A. S., and Flood, C. (1962). F. clin. Invest., 41, 2093.

Ulick, S., Laragh, J. H., and Lieberman, S. (1958). Trans. Ass. Amer.

Urquhart, J., and Davis, J. O. (1963). Mod. Conc. cardiovasc. Dis., 32, 781.

Wilson, C., and Byrom, F. B. (1939). Lancet, 1, 136.

and Pickering, G. W. (1938). Clin. Sci., 3, 343

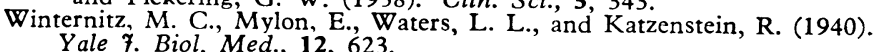

Wolff, H. P.. Koczorek, K. R., and Buchborn, E. (1957). Lancet, 2, 63.

Yoshinaga, K., Aida, M., Maebashi. M., Sato, T., Abe, K., and Miwa, I. (1963). Tohoku 尹. exp. Med., 80, 32 . 